\title{
Micelles, Dispersions, and Liquid Crystals in the Catanionic Mixture Bile Salt-Double-Chained Surfactant. The Bile Salt-Rich Area
}

\author{
Eduardo F. Marques,, ,t, Oren Regev, ${ }^{\S}$ Håkan Edlund," and Ali Khan ${ }^{\dagger}$ \\ Physical Chemistry 1, Center for Chemistry and Chemical Engineering, P.O. Box 124, \\ Lund University, Lund SE-221 00, Sweden, Department of Chemical Engineering, Ben-Gurion \\ University of the Negev, P.O. Box 653, 84105 Ber-Sheva, I srae, Departamento de Química, \\ Universidade de Coimbra, 3049 Coimbra, Portugal, and Department of Chemistry and Process \\ Technology, Chemistry, Mid Sweden University, SE-851 70 Sundsvall, Sweden
}

Received February 15, 2000. In Final Form: August 1, 2000

\begin{abstract}
The phase behavior and phase structure for the catanionic pair sodium taurodeoxychol ate-didodecyldimethylammonium bromide (DDAB) are investigated, at $25^{\circ} \mathrm{C}$. A combination of techniques is used including light and electron microscopy, small-angle X-ray scattering, and pulsed field gradient NMR self-diffusion. Thebilesalt micellar solution incorporates largeamounts of thedouble-chained amphiphile, with the solution region extending to equimolarity. On the contrary, the hexagonal liquid-crystall ine phase is destabilized by the addition of small amounts of DDAB. At equimolarity, coacervation instead of precipitation is observed, with formation of a viscous isotropic solution and a very dilute one. In the water-rich part of the phase diagram, a peculiar type of phase separation occurs, involving the formation of very fine bluish dispersions and a region of coexistence of two dispersions (double dispersion region). Microscopy and self-diffusion data for the solution region indicate limited growth of the mixed micelles. Large domains in which themicellar structureappears to be maintained areimaged in thebluish dispersi ons by el ectron microscopy. No other type of aggregate such as vesicles or preci pitates is observed in the dilute bile salt-rich area of this mixture.
\end{abstract}

\section{Introduction}

The bile acid salts are surfactants of vital biological importance. They play an active rol ein theemulsification of fats in thegut and aid in theexcretion process of lecithin and chol esterol. ${ }^{1-3}$ Thesurfaceand aggregation properties of aqueous solutions of bile salts have been scrutinized over decades. ${ }^{4-13} \mathrm{It}$ is known that the molecules form micelles of small aggregation numbers and that these aggregates grow with concentration. ${ }^{8,9,14-16}$ Between the isotropic solution and the hydrated crystals, a narrow region of hexagonal liquid crystal formation has been recently found for various types of bile salts. ${ }^{17,18}$ The

* To whom correspondence may be addressed. E-mail: eduardo.marques@fkem1.lu.se or emarques@ci.uc.pt.

+ Lund University.

₹ Universidade de Coimbra.

$\S$ Ben-Gurion University of the Negev.

"Mid Sweden University.

(1) Carey, M. C.; Small, D. M. Am. J . Med. 1970, 49, 590.

(2) Small, D. M. The Bile Acids; Nair, P. P., Kritchevsky, D., Eds.; Plenum Press: New York, 1971.

(3) Borgström, B. Int. Rev. Physiol. 1977, 12, 305.

(4) Ekwall, P. J. Colloid Sci. 1954, 8, 66.

(5) Blow, D. M.; Rich. A. J. Am. Chem. Soc. 1960, 82, 3566.

(6) Fontell, K. Kolloid-Z. Z. Polym. 1971, 244, 246.

(7) Carey, M. C.; Small, D. M. Arch. Intern. Med. 1972, 130, 506

(8) Mysels, K. J. Hepatology 1984, 4, $80 \mathrm{~S}$.

(9) Mazer, N. A.; Carey, M. C.; Kwasnick, R. F.; Benedek, G. B. Biochemistry 1979, 18, 3064.

(10) Murata, Y.; Sugihara, G.; Fukushima, K.; Tanaka, M.; Matsushita, K. J. Phys. Chem. 1982, 86, 4690.

(11) Kratohvil, J . P.; H su, W. P.; Kwok, D. I. Langmuir 1986, 2, 256.

(12) Giglio, E.; Loreti, S.; Pavel, N. V.J . Phys. Chem. 1988, 92, 2858.

(13) Briganti, G.; D’Archivio, A. A.; Galantini, L.; Giglio, E. Langmuir 1996, 12, 1180.

(14) Lindman, B.; Kamenka, N.; Brun, B. J . Colloid Interface Sci.

1976, 56, 238.

(15) Kratohvil, J . P. Adv. Colloid Interface Sci. 1986, 26, 131.

(16) Li, G.; M CGown, L. B. J . Phys. Chem. 1994, 98, 13711.

(17) Edlund, H.; Khan, A.; La Mesa, C. Langmuir 1998, 14, 3691. uncommon properties of these surfactants are directly linked to their molecular structure, in particular the absence of flexibleal kyl chainsand thedual polar/nonpolar character of thehydroxylated steroid ring. Theaggregation process is essentially due to hydrophobic "back-to-back" interactions, but intermolecular hydrogen bonding seems also to play a rol e. $10,16,19$

Owing to the natural occurrence of bilesalts in complex mixtures with other compounds, phase behavior investigations have naturally extended to ternary and quaternary systems where bile salt is mixed with phospholipids, ${ }^{20-27}$ monoglycerides, ${ }^{28}$ or several common synthetic surfactants. ${ }^{29-32}$ Various types of micellar and vesicular aggregates have been directly imaged in human bile. ${ }^{33} \mathrm{In}$

(18) Marques, E. F.; Edlund, H.; La Mesa, C.; Khan, A. Langmuir 2000, 16, 5178-5186

(19) J u, C.; Bohne, C. J . Phys. Chem. 1996, 100, 3847.

(20) Ulmius, J .; Lindblom, G.; Wennerström, H.; J ohansson, L. B.Å.; Fontell, K.; Söderman, O.; Arvidson, G. Biochemistry 1982, 21, 1553. (21) Thurmond, R. L.; Lindblom, G.; Brown, M. F. Biophys. J . 1991 60,728

(22) Walter, A.; Vinson, P. K.; Kaplon, A.; Talmon, Y. Biophys J $1991,60,1315$

(23) Edwards, K.; Almgren, M. Langmuir 1992, 8, 824

(24) Pedersen, J. S.; Egelhaaf, S. U.; Schurtenberger, P. J . Phys. Chem. 1995, 99, 1299.

(25) Li, C.-Y.; Wiedmann, T. S. J . Phys. Chem. 1996, 100, 18464

(26) Luk, A. S.; Kaler, E. W.; Lee, S. P. Biochemistry 1997, 36, 5633.

(27) Cohen, D. E.; Thurston, G. M.; Chamberlin, R. A.; Benedek, G.

B.; Carey, M. C. Biochemistry 1998, 37, 14798.

(28) Svärd, M.; Schurtenberger, P.; F ontell, K.;J önsson, B.; Lindman, B. J . Phys. Chem. 1988, 92, 2261. 327.

Barry, B. W.; Gray, G. M. T. J . Colloid Interface Sci. 1975, 52,

(30) La Mesa, C.; Khan, A.; Fontell, K.; Lindman, B. J . Colloid Interface Sci. 1985, 103, 373-391.

(31) Wu, K.; McGown, L. B. J . Phys. Chem. 1994, 98, 1185.

(32) Swanson-Vethamuthu, M.; Almgren, $M_{\text {.; }}$ Bergenståhl, B. Mukhtar, E. J. Colloid Interface Sci. 1996, 178, 538.

(33) Kaplun, A.; Talmon, Y.; Konikoff, F. M.; Rubin, M.; Eitan, A.; Tadmor, M.; Lichtenberg, D. FEBS Lett. 1994, 340, 78. 
a

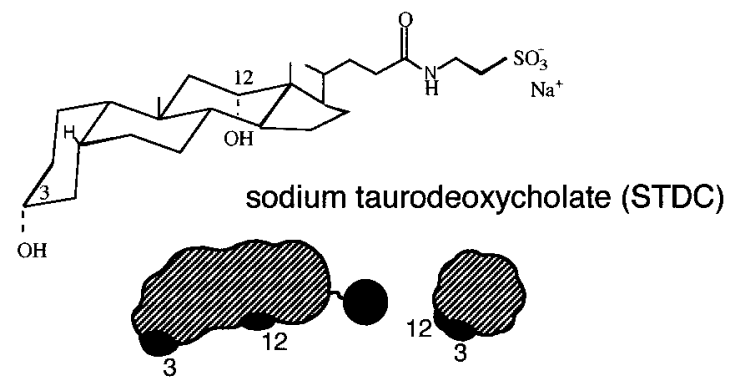

b

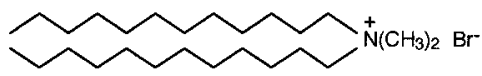

didodecyldimethylammonium bromide (DDAB)

Figure 1. Molecular structure of the catanionic pair: (a) the bile salt sodium taurodeoxycholate $(3 \alpha, 12 \alpha$-dihydroxy- $5 \beta$ taurochol an-24-oic acid salt), STDC, together with a longitudinal and transverseview of themolecule; (b) the double-chained surfactant didodecyl dimethylammonium bromide (DDAB).

thesodium cholate-lecithin-water system, ${ }^{20}$ for example, extensivemicellar solution and lamellar liquid-crystalline phases areformed, as well as hexagonal and cubic phases, indicating strong amphiphilicassociation. Mixed systems comprising sodi um deoxychol ateand anionic surfactants, such as sodium bis(2-diethylhexyl)sulfosuccinate (AOT), sodium didodecyl sulfate (SDS), Triton X-100, and hexadecyltrimethylammonium bromide (CTAB $)^{32,34}$ have al so been studied. In the catanionic system sodium deoxycholate-CTAB, separation into two coexisting liquids (coacervation) is seen at equimolar ratio, instead of precipitation. ${ }^{32}$ Borne out from the latter studies is the great versatility of bile salts to associate with different surfactants, either oppositely or similarly charged.

In the current work, the associative behavior between a bile salt and a double-chained surfactant of opposite charge is addressed. This type of catani onic mixture has not been investigated previously, and it is anticipated to yield interesting features, sincetheaggregation properties of thetwoamphiphiles in water arevery different. Sodium taurodeoxycholate (STDC), one of the most widespread bile acids, and the double-chained surfactant didodecyldi methylammonium bromi de (DDAB) are the catanionic pair to be investigated at room temperature (Figure 1). Only the bile salt-rich area is reported here, while the DDAB-rich one will be addressed in a separatework. The interplay between the electrostatic interactions and different geometric packing properties of the two amphiphiles will dictate the phase behavior features in the STDC-DDAB mixture. The DDAB surfactant, with a packing parameter of about 0.8 , has a tendency to form lamellar liquid crystal $\mathrm{s}^{35-37}$ and, at high dilution, vesicle dispersions, ${ }^{38-40}$ while the bile salt molecule packs into mi cellar-likeaggregates. Thenet outcomeof electrostatid packing interactions at both macroscopic level (phase

(34) La Mesa, C.; Khan, A.; Fontell, K.; Lindman, B. J . Colloid Interface Sci. 1985, 103, 373.

(35) Fontell, K.; Ceglie, A.; Lindman, B.; Ninham, B. Acta Chem. Scand. 1986, A40, 247.

(36) Zemb, T.; Gazeau, D.; Dubois, M.; Gulik-Krzywicki, T. Europhys. Lett. 1993, 21, 759.

(37) Marques, E.; Khan, A.; Miguel, M. G.; Lindman, B. J . Phys. Chem. 1993, 97, 4729.

(38) Miller, D. D.; Bellare, J . R.; Evans, D. F.; Talmon, Y.; Ninham B. W. J . Phys. Chem. 1987, 91, 674.

(39) Dubois, M.; Zemb, T. Langmuir 1991, 7, 1352.

(40) Marques, E. F.; Regev, O.; Khan, A.; Miguel, M. G.; Lindman,

B. J . Phys. Chem. 1999, 103, 8353. behavior) and microscopic level (aggregate structure) remains to be seen.

The strong associative phase behavior in catanionic systems usually leads to the formation of crystalline precipitates around equimolarity and several "novel" liquid-crystallinephases. 41,42 This type of behavior is seen inter alia for the systems DDAB-SDS ${ }^{37}$ and DDABAOT . ${ }^{43}$ At low concentrations, with slight excess of one of the ionic amphiphiles, mixed micelles denoting growth (to rodlike or disklike micelles) and stable, spontaneous vesicles are often formed. ${ }^{40,44-46}$ In this context, several particular issues areaddressed here: (i) type of associative phase separation (precipitation, coacervation, or liquid crystal formation); (ii) nature of micellar growth; (iii) possibleformation of vesicles and "novel" liquid-crystalline phases.

\section{Experimental Section}

2.1. Materials and Sample Preparation. Sodium taurodeoxycholate (STDC), $0.5 \mathrm{~mol}$ of $\mathrm{H}_{2} \mathrm{O} / \mathrm{mol}$, more than $97 \%$ in purity, was purchased from Sigma and used without further purification. Didodecyldi methylammonium bromide (DDAB) of high purity was obtained from Tokyo Kasei. $\mathrm{D}_{2} \mathrm{O}$ supplied by $\mathrm{Dr}$. Basel, Switzerland, was used in all samples for self-diffusion NMR. The molecular structure of STDC and DDAB is shown in parts $a$ and b of Figure 1, respectively. The two hydroxyl groups $(\alpha \mathrm{C}-3$ and $\alpha \mathrm{C}-12$ ) in STDC point to the same side of the steroid ring, giving it a polar and a nonpolar side. The relative spacial position of thetwocarbon atoms is easily visualized in theshaded space filling models in Figure la. The samples were prepared by weighing directly the two surfactant solids into glass vials and thoroughly mixing them in water end-over-end for at least $24 \mathrm{~h}$.

2.2. Phase Behavior and Structure Determination. Phase Diagram. The phasediagram in Figure2 resultsfrom theanalysis of ca. 150 samples in the course of at least 6 months. Thesamples were inspected by the naked eye and between crossed polaroi ds in order to check for birefringence. Phase assignment is further done on the basis of combined polarizing microscopy, cryogenic transmission electron microscopy (cryo-TEM), self-diffusion NMR, and small angleX-ray scattering (SAXS). Theuncertainty of boundaries in the phase diagrams is ca. \pm 2 wt \% in Figure 2 and less than \pm 0.5 wt \% in Figure 4 .

Light Microscopy. An Axioplan Universal polarizing light microscope (Carl Zeiss) was used, equipped with differential interference contrast (DIC) lenses and a high-sensitive videocamera system, with image processor Argus-20 (Hamamatsu Photonics, J apan).

Small-AngleX-rayScattering(SAXS). Themeasurements were carried out in a K ratky camera system equipped with a positionsensitive detector with 1024 channels of width $53 \mu \mathrm{m}$. The Cu $\mathrm{K} \alpha$ radiation of wavelength $1.542 \AA$ was used, and the sampleto-detector distance was $277 \mathrm{~mm}$. The samples were prepared in a paste holder between thin mica windows. The temperature was regulated by a Peltier element and the camera vol ume kept under vacuum to minimize air scattering.

Cryogenic Transmissi on Electron Microscopy (cryo-TEM). The cryo-TEM method 47,48 was used for direct imaging of dilute solutions and bluish dispersions. When artifact-free films are

(41) J okela, P.; önsson, B.; Khan, A.J . Phys. Chem. 1987, 91, 32913298

(42) Khan, A.; Marques, E. Catanionic Surfactants. In Specialists Surfactants; Robb, I. D., Ed.; Blackie Academic and Professional, an imprint of Chapman \& Hall: London, 1997; pp 37-76.

(43) Caria, A.; Khan, A. Langmuir 1996, 12, 6282.

(44) Kaler, E. W.; Murthy, A. K.; Rodriguez, B. E.; Zasdzinski, J . A. N. Science 1989, 245, 1371 .

(45) Kaler, E. W.; Herrington, K. L.; Murthy, A. K.; Zasadzinski, J . A. J . Phys. Chem. 1992, 96, 6698-6707.

(46) Marques, E. F.; Regev, O.; Khan, A.; Miguel, M. G.; Lindman, B. J . Phys. Chem. B 1998, 102, 6746.

(47) Bellare, J . R.; Davis, H. T.; Scriven, L. E.; Talmon, Y.J . Electron Microsc. Technol. 1988, 10, 87

(48) Vinson, P. K. "Cryo-TEM, carbon-coated holey polymer film"; The 45th Annual Meeting of theE lectron Microscopy Society of America, San Francisco, CA, 1987. 
prepared, this method is powerful in thestructural investigation of surfactant systems. ${ }^{49}$ Vitrified samples were prepared and imaged according to the procedure described in previous works. ${ }^{40,46}$

Pulsed-Fiedd Gradient (PFG) NMR Self-Diffusion. The PFG techniquefor measuring self-diffusion coefficients is very useful for structural and dynamic studies in surfactant systems. ${ }^{50,51}$ The method is based on a combination of radio frequency ( $\mathrm{rf}$ ) pulses and magnetic field gradient pulses, as described in detail in specialist reviews. ${ }^{52,53}$ In this work, measurements were done in a Bruker DMX200 spectrometer at $25{ }^{\circ} \mathrm{C}$, with a probe providing a maximum gradient of $9 \mathrm{~T} / \mathrm{m}$. The water and the surfactant self-diffusion were measured by means of the basic $\mathrm{H}$ ahn echo and the stimulated echo sequence, respectively, as described in detail in previous work. ${ }^{18,46}$

\section{Results and Discussion}

3.1. Overview of Phase Behavior. The phase be havior for the catanionic system STDC-DDAB - water, in the bile salt-rich area, at $25^{\circ} \mathrm{C}$ is depicted in the triangular phase diagram in Figure 2. The compositions are given in wt \% for the three chemical species and represented by a point in the triangle. Throughout the discussion, the surfactant mixing ratio is given by the DDAB molar fraction, $\mathrm{X}_{\mathrm{DDAB}}=\mathrm{n}_{\mathrm{DDAB}} /\left(\mathrm{n}_{\mathrm{STDC}}+\mathrm{n}_{\mathrm{DDAB}}\right)$, where $n_{i}$ is the number of moles of component $i$ in the sample. It should bekept in mind that catanionic mixtures are, strictly speaking, four-component systems, ${ }^{54,55}$ but often, on the basis of experimental data, their phase behavior can be conveniently depicted by ternary phase diagrams. $37,43,56$

At room temperature, the bile salt STDC is soluble in water up to about $26 \mathrm{wt} \%$. The isotropic solution contains at the critical micelle concentration (cmc) micellar aggregates of small aggregation number, and as the amphiphile concentration rises, the aggregates grow into larger micelles. In the range 37-60 wt \%, an anisotropic liquid-crystalline phase is formed, as recently shown by Edlund et al. ${ }^{17}$ It is now known, contrary to previous notions, that several bile salts form a common type of anisotropicliquid-crystallinephase. ${ }^{18} \mathrm{DDAB}$, on theother hand, is a highly insoluble surfactant, forming at room temperature two lamellar liquid-crystalline phases, a concentrated one and a dilute one. Bel ow 3 wt \% in water, the amphiphile forms a lamellar dispersion, where different types of vesicular structures are identified (uni-, bi-, and multilamellar vesicles). ${ }^{38-40,57}$

As can be seen in Figure 2, the addition of the bilayerforming surfactant to the bile salt solution results in several interesting effects. Up to about 20 wt \% STDC, the maximum amount of DDAB solubilized is roughly constant at $\mathrm{X}_{\mathrm{DDAB}}=0.3$. The solutions are clear and increasingly viscous. For more than 20 wt \% STDC, the solution region forms a long "neck" which extends up to equimolar composition. This observation implies that increasing amounts of DDAB are taken up by the solution phase as the STDC concentration rises. The equi-

(49) Talmon, Y. Ber. Bunsen-Ges. Phys. Chem. 1996, 3, 364.

(50) Lindman, B.; Söderman, O.; Wennerström, H. NMR studies of surfactant systems. In Surfactant Solutions, New Methods of I nvestigation; Zana, R., Ed.; Marcel Dekker: New York, 1987.

(51) Söderman, O.; Stilbs, P. Prog. Nucl. Magn. Reson. Spectrosc. 1994, 26, 445.

(52) Stilbs, P. Prog. Nudl. Magn. Reson. Spectrosc. 1987, 19, 1

(53) Price, W. S. Concepts Magn. Res. 1997, 9, 299.

(54) J okela, P.; J önsson, B.; Wennerström, H. Prog. Colloid Polym. Sci. 1985, 70, 17-22.

(55) Thalberg, K.; Lindman, B. Polyelectrolyte-ionic surfactant systems. In Surfactantsin Solution; Mittal, K., Shah, O. O., Eds.; Plenum Press: New York, 1991.

(56) Regev, O.; Khan, A. J . Coll loid Interface Sci. 1996, 182, 95.

(57) Regev, O.; Khan, A. Prog. Colloid Polym. Sci. 1994, 97, 298.

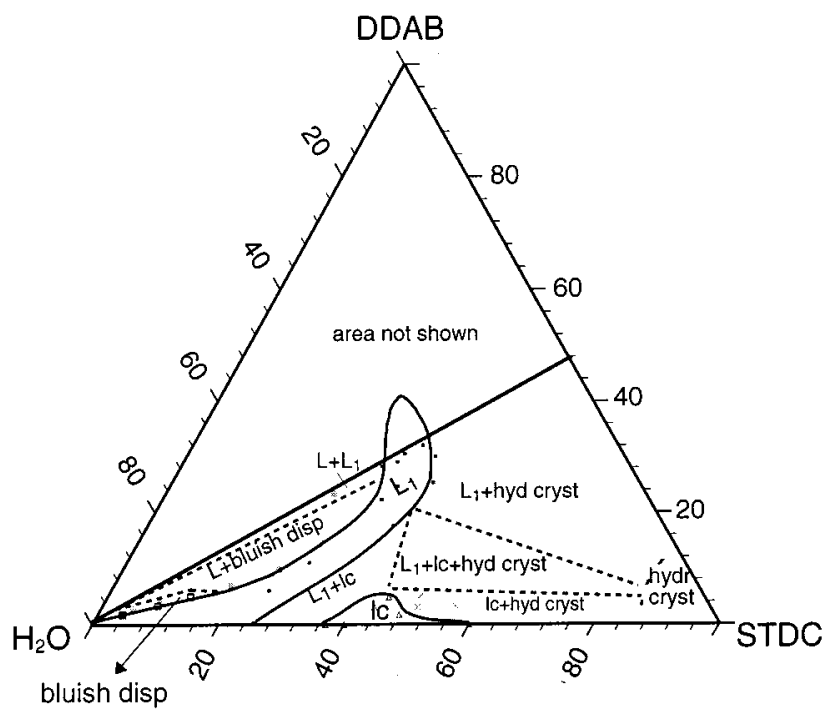

Figure 2. Phasebehavior for thesystem STDC-DDAB - water at $25^{\circ} \mathrm{C}$, in the bile salt-rich area. Notations are as follows: $L_{1}$, isotropic solution; $L$, very dilute isotropic sol ution; bluish disp, bluish dispersion; Ic, liquid crystal; cryst, hydrated crystals. The straight line drawn is the equimolarity line.

molar solution phase, which has a narrow stability range (36-40 wt \% STDC and 28-32 wt \% DDAB), is al so clear and extremely viscous. I incorporates only a small excess of DDAB prior to phase separation (Figure 2). Along the equimolar line, the concentrated $\mathrm{L}_{1}$ phaseis in equilibrium with a low-viscosity cl ear liquid ( $L$ in Figure 2 ), which is al most "pure" water, i.e., a coacervation region is formed. Between the $L_{1}$ phase and the two-phase $L_{1}+L$ region (where both solutions are cl ear), there is another liquidliquid coexistenceregion in which at least one of theliquids is bluish and weakly translucent $(\mathrm{L}+$ bluish disp region in Figure 2). As discussed further, the macroscopic appearance of the two coexisting liquids changes drastically as $\mathrm{X}_{\mathrm{DDAB}}$ increases toward equimolarity (Figure 5 ). Up to about 20 wt $\%$ STDC and $X_{\text {DDAB }} \approx 0.30-0.35$, the bluish dispersion shows macroscopically homogeneous, forming a narrow strip in the phase diagram (Figure 2). The liquid-crystalline phase (Ic region in Figure 2) incorporates smaller amounts of DDAB than the solution phase, with no more than 11 mol \% DDAB (at 45 wt \% STDC) being solubilized. As the STDC concentration increases beyond 45 wt \%, increasingly lower amounts of DDAB are taken up by thelc phase. Beyond the solubilty limits, a two-phaseregion $I_{c}+L_{1}$ and a three-phaseregion $\mathrm{L}_{1}+\mathrm{IC}+$ hydrated crystals are formed.

3.2. The Liquid-Crystalline Phase. Both SAXS measurements and optical textures show that thelc phase in the STDC-DDAB - water system is of the hexagonal type. In Figure 3a, a series of Bragg reflections in the order 1:1.73:1.98:2.66 are detected for a representative sampleat 43.2 wt \% STDC/3.02 wt \%DDAB. The q values are in good agreement with the expected $1: \sqrt{ } 3: \sqrt{ } 4: \sqrt{ } 7$ sequence for a hexagonal liquid-crystalline phase. To be noticed is the low intensity of the correlation peaks and the fact that the first (01) reflection is of comparable intensity to the successive (11), (21), and (22) peaks. F or this sample, a d-spacing of $4 \mathrm{~nm}$ and a nearest-neighbor distance between cylinders of $4.6 \mathrm{~nm}$ were obtained. We note that these values are compatible with a hexagonal phase of the reverse type (even if its structure may not follow the conventional type), as previously proposed for the binary bile salt-water Ic phase. ${ }^{17,18}$ In the polarizing microscope, a nongeometric, striated pattern, typical of a hexagonal phase, is observed (Figure $3 \mathrm{~b}$ ). ${ }^{2} \mathrm{H}$ NMR spectra 
a
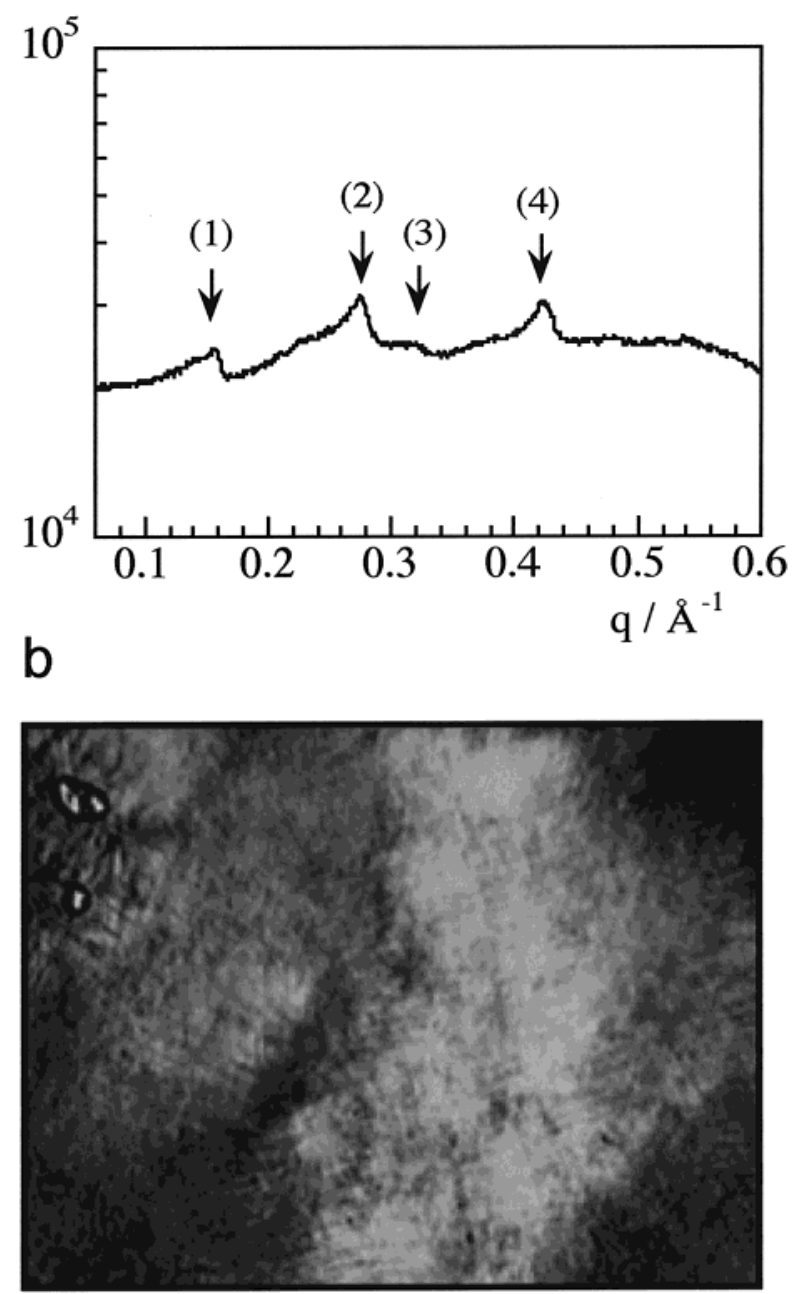

Figure 3. Structural determination of theliquid crystal (at 41 wt \% STDC, 4 wt \% DDAB): (a) slit-smeared SAXS pattern, where the numbers indicate the nth order correlation peak ascribed toa hexagonal lattice; (b) nongeometric striated texture at the polarizing microscope, typical of a hexagonal phase.

recorded for several samples within the Ic region varied between an incipient quadrupolar splitting and a broad singlet, depending on sample composition, similar to data reported for the bile salt-water systems. ${ }^{18}$

3.3. Structural Investigation of Solutions and Bluish Dispersions. A. Macroscopic View of Phase Separation. The phase behavior in the water-rich area of the catanionic mixture is depicted in Figure 4, with a detailed view of the area between the $L_{1}$ phase and the equimolar line. For easier visualization, a phase map is shown where the sample composition is pl ot as DDAB wt $\%$ vS STDC wt \%. Some peculiar aspects of phase separation areobserved. Fivedifferent areas areidentified between the $L_{1}$ phase (at roughly constant $X_{\mathrm{DDAB}}=0.30$ ) and the equimolarity line (at $X_{D D A B}=0.50$ ). Initially, a bluish nonbirefringent liquid is seen (region I). This region is followed by a liquid-liquid coexistence region (region II): the upper liquid is bluish, turbid, viscous, and flow birefringent; the bottom liquid is bluish but translucent, nonbirefringent, and of much lower viscosity. The phase separation process is clear-cut within minutes after vigorous shaking, with development of a clear meniscus, denoting a high interfacial tension between the liquids. Therefore, this region is designated as a doubledispersion (not to be confused with double emulsion, a particular

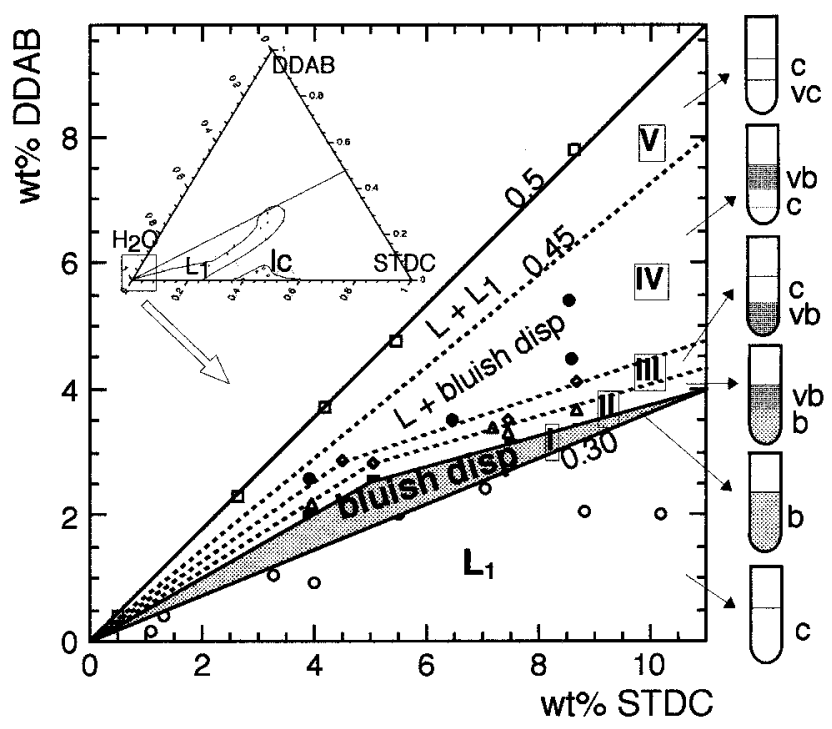

Figure 4. Detailed phase behavior for the system STDCDDAB-water at $25{ }^{\circ} \mathrm{C}$ in the water-rich corner. The insert shows the compl ete phase diagram. In the right-hand si de the macroscopic appearance of the samples in the test tube is depicted. Legend: c, colorless; b, bluish (low-viscosity); vb, viscous bluish (high-viscosity); vc, viscous clear.

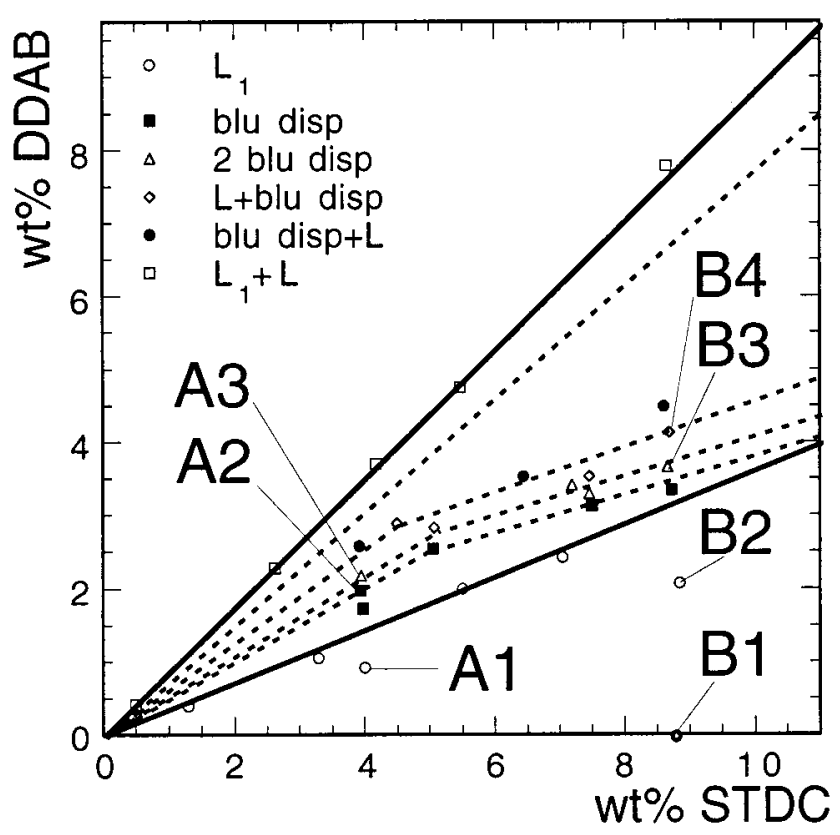

Figure 5. Location of the samples imaged by cryo-TEM and light microscopy in the dilute phase diagram.

type of oil-water emulsion ${ }^{58}$ ). Region III presents a dense viscous bluish liquid in coexistence with a lower-density clear solution. In region IV, the density of the two phases is reversed. Finally, in regi on $V$ two clear liquids coexist, with the concentrated viscous solution being the highest density liquid.

B. Electron and Light Microscopic Study. To probe themicrostructure of thesolution and dispersions observed in Figure 5, both cryo-TEM and light microscopy were carried out. The two techniques in combi nation allow the visualization of aggregate sizes ranging from 5 to 1000 $\mathrm{nm}$ (cryo-TEM) to those larger than $1 \mu \mathrm{m}$ (light microscopy). Thecryo-TE M results for different regions in F igure

(58) Evans, D. F.; Wennerström, H. The Colloidal Domain: Where Physics, Chemistry, Biol ogy and Technol ogy Meet, 2nd ed.; Wiley-VCH: New York, 1999. 
Table 1. Cryo-TEM Observations in the Isotropic Solution and Bluish Dispersion of the STDC-DDAB-Water System at $25^{\circ} \mathrm{C}$

\begin{tabular}{|c|c|c|c|c|c|}
\hline sample & $\begin{array}{l}\text { STDC } \\
\text { (wt \%) }\end{array}$ & $\begin{array}{l}\text { DDAB } \\
\text { (wt \%) }\end{array}$ & $X_{\text {DDAB }}$ & $\begin{array}{c}\text { phase } \\
\text { behavior }\end{array}$ & cryo-TEM observns \\
\hline A1 & 4.0 & 0.9 & 0.20 & $\mathrm{~L}_{1}$ & sph mic \\
\hline A2 & 3.9 & 2.0 & 0.36 & region I & domains \\
\hline A3 & 3.9 & 2.1 & 0.38 & region II & domains \\
\hline B1 & 8.7 & & 0 & $\mathrm{~L}_{1}$ & sph mic \\
\hline B2 & 8.7 & 2.2 & 0.21 & $\mathrm{~L}_{1}$ & sph mic \\
\hline B3 & 8.7 & 3.3 & 0.30 & region II & sph mic + domains \\
\hline B4 & 8.6 & 3.9 & 0.32 & region III & sph mic + domains \\
\hline
\end{tabular}

a Sph mic refers to spheroidal micelles (ca. $5 \mathrm{~nm}$ ). Domains refer to large domains $(0.2-1 \mu \mathrm{m})$ with fine structure.

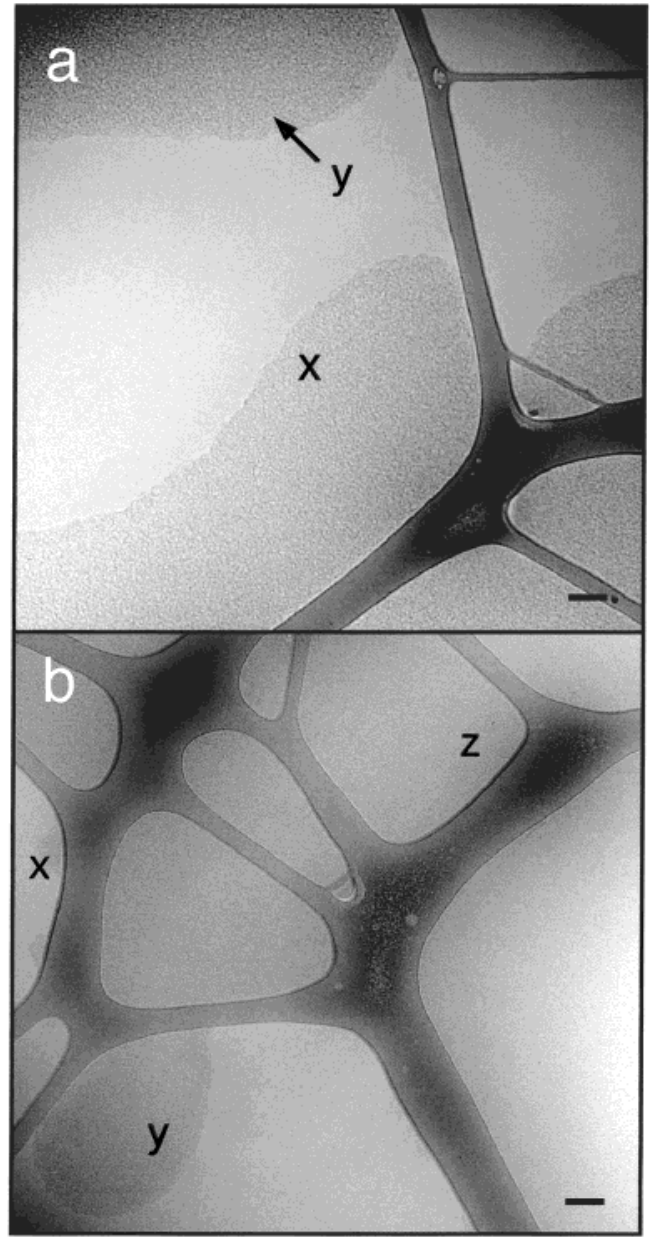

Figure 6. Cryo-TEM imaging of samples in the bluish dispersions of the STDC-DDAB-water system at $25^{\circ} \mathrm{C}$. (a) Bluish dispersion (region I ), at 3.9 wt \% STDC, 2.2 wt \% DDAB (sample A2). Large domains with meshlike, porous structure (x) and sandlikeappearance of domain edge (y). (b) U pper phase of double dispersion (region II), at $8.7 \mathrm{wt} \%$ STDC, $3.3 \mathrm{wt} \%$ DDAB (sampleB3). Small (x), medium (y), and large(z) meshlike domains. Bars $=100 \mathrm{~nm}$.

5 aresummarized in Table1. Representativemicrographs areshown in Figure 6. The neat bilesalt-water solutions (sample B1) show small, spheroidal micellar aggregates of about $5 \mathrm{~nm}$ in size. Upon DDAB addition (at $\mathrm{X}_{\mathrm{DDAB}}=$ 0.2 ), small micellar aggregates are still present (samples $A 1$ and $B 2$ ); besides, large domains of irregular sizein the order of 100-1000 nm appear in some areas of the film. The bluish region I displays an even higher number of such large structures, as seen in Figure 6a (sample A2). It is possible to observe large domains, $500-1000 \mathrm{~nm}$ in size, with a fine dotted structure ( $x$ in Figure 6a). The interior structure of the domains resembles an array of densely packed micelles. To be noted is the grainy appearance of the domain edge (y in Figure 6a). Similar types of structures are depicted in Figure $6 \mathrm{~b}$ for the upper phase of a sample in region II (sample B3). Small (x), medium (y), and larger domains filling the grid hole (z) can beseen. Thesemicrographs suggest that theobserved domains are responsi ble for the bluish appearance of the dispersions in regions I, II, and III, due the scattering of visible light (Tyndall effect). The domains are clearly not crystallites nor any well-defined surfactant aggregate, such as a vesicle or a large micelle.

Togain further structural insight, light microscopy was al so carried out for the bl uish dispersions. In Figure 7, a sequence of light micrographs is shown for sample A2. It is clear that the bluish liquid consists of a very fine dispersion of droplets of oneliquid in another. Thedroplets are in Brownian motion and show fast dynamics of coal escence. The droplet sizevaries from 1 to $100 \mu \mathrm{m}$, and it is even possibletosee giant droplets containing clusters of smaller ones. From panels a to din Figure 7, a sequence of events in the time span of 1 min is monitored, during which thearea under observation is slightly heated above room temperature by the light beam. In Figure 7a many small droplets are seen in the giant cluster marked as $\mathrm{x}$; in Figure 7d, most of small dropl ets have coalesced into the giant droplet. The process of fusion of a single droplet (marked by an arrow) can be followed in Figure 7.

Figure 8 shows the imaging for the upper (a) and lower (b) bluish liquid phases of sample A3 (double dispersion region). The main microscopic difference between thetwo liquids is that the low-density liquid has larger droplets than the high-density one. The composition of the two liquids is likely to differ. It can be speculated that the upper phase is a dispersion of $L$ in $L_{1}$ (low density), while the lower phase is a dispersion of $L_{1}$ in $L$. The flow birefringence of the upper phase is probably due to the anisotropy produced by the shear-induced droplet deformation when thesampleis quickly rotated. U pon heating to $40^{\circ} \mathrm{C}$ for a few minutes, thetwo bluish liquids transform into a singlewhiteturbid dispersion. Similar observations aremadein regions $\mathrm{I}, \mathrm{I}$, and III , indicating that thesystem changes from a double dispersion to a typical strong dispersion upon increasing temperature.

The combined data from electron and light microscopy show that in the region above the $L_{1}$ phase a stable and finely divided dispersion is formed. The dispersion in region I consists then of droplets of the concentrated $L_{1}$ phasein a very diluted sol ution (L). Thus, what is viewed in the cryo-TEM pictures is most certainly the fine structure of the dispersed $L_{1}$ domains, which appear to contain small mixed micellar aggregates.

C. NMR Self-Diffusion Study. Self-diffusion measurements were carried out for samples in the $L_{1}$ phase and bluish dispersions, to obtain an estimation of aggregate/domain sizes. The self-diffusion coefficients (D) for the two surfactants and for water are listed in Tables 2 and 3, respectively. Theresul ts at constant $4 \mathrm{wt} \%$ STDC and increasing $X_{D D A B}$ are shown in Figure 9a. In the $L_{1}$ phase both surfactants havesimilar $D$ values. $D$ decreases from $9.1 \times 10^{-11} \mathrm{~m}^{2} \mathrm{~s}^{-1}$ for the neat STDC solution to 5.1 $\times 10^{-11} \mathrm{~m}^{2} \mathrm{~s}^{-1}$ for a solution at $X_{\mathrm{DDAB}}=0.20$, showing that the micellar growth is not pronounced. In effect, the aggregate hydrodynamic radius $R_{H}$, estimated from the Stokes-Einstein equation, uncorrected for intermicellar obstruction effect, increases from $21 \AA$ for the neat bile salt micelle to $44 \AA$ for the mixed aggregate at $\mathrm{X}_{\mathrm{DDAB}}=$ 0.20 (Figure 9b). 


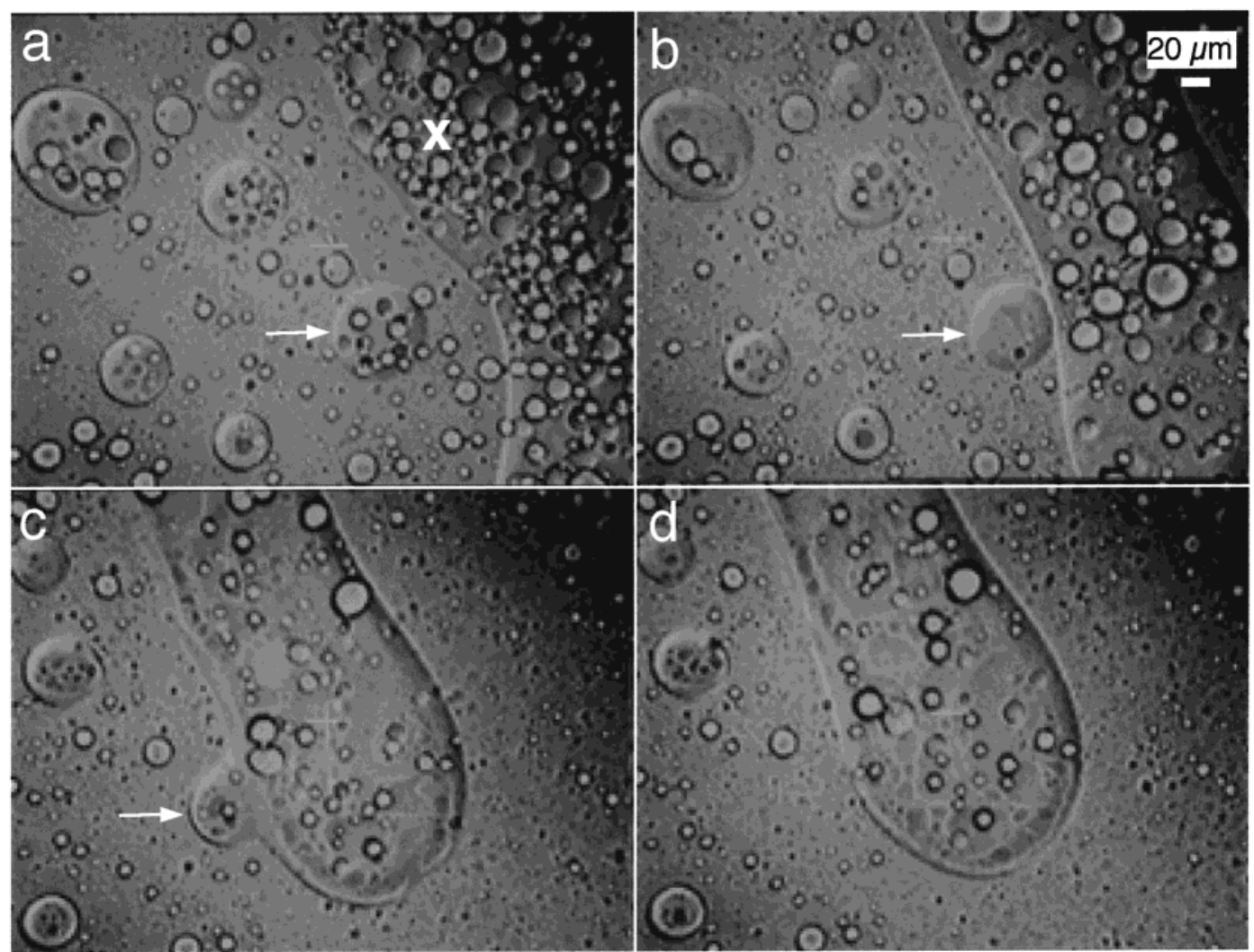

Figure 7. I maging of a bluish dispersion, at $3.9 \mathrm{wt} \%$ STDC, $2.0 \mathrm{wt} \%$, in the light microscope. From (a) to (d), there is a time delay of ca. $60 \mathrm{~s}$. The arrow points to the coalescence process of a small droplet. Note also that the small droplets clustered inside the giant droplet (marked with $\mathrm{x}$ ) eventually coalesce. Since the dispersion is stable at room temperature, this effect appears to result from the slight increase in temperature provided by the light beam.

In thebluish region (region I), however, a different trend is observed. The DDAB diffusion is consistently slower than the STDC one, by a 1.5-3-fold factor. As $X_{D D A B}$ increases, the discrepancy between the two $D$ values increases. It was also possible to measure the surfactant diffusion in the two bluish dispersions of region II. The coefficients for the upper phase are considerably smaller than those for the lower phase, as expected from previous viscosity observations. $R_{H}$ values obtained from theDDAB diffusion (Figure 9b) yield 17 and $570 \mathrm{~nm}$ for the lower and the upper phase, respectively. Further self-diffusion measurements made for more concentrated samples in the $L_{1}$ solution and bluish dispersion regions are listed in Table 2. The $D$ values obtained for the equimolar sample at 34.6 wt \% STDC/30.5 wt \% DDAB, roughly in the range of $1 \times 10^{-12} \mathrm{~m}^{2} \mathrm{~s}^{-1}$ for both surfactants, suggest also the presence of small mixed aggregates. The estimated radii $\left(R_{H}\right)$ in Table 1 allow only qualitative discussions, since at these surfactant concentrations interaggregate obstruction effects have an important contribution to the measured D (consequently, the radii in Table 2 are overestimated). For other $L_{1}$ samples in Table 2, with $X_{\text {DDAB }}$ $=0.2-0.35$, both surfactants show similar $D$ values $(6-7$ $\left.\times 10^{-13} \mathrm{~m}^{2} \mathrm{~s}^{-1}\right)$, meaning slightl y sl ower diffusion than in the equimolar solution.

Water self-diffusion provides further information on the aggregation phenomena. The reduced self-diffusion coefficients, $\mathrm{D} / \mathrm{D}_{\mathrm{o}}$ in Table 3 , give a qualitative indication of the obstructing volume for free water diffusion. Only Gaussian (free) diffusion is observed for both solutions and dispersions, i.e., only a single diffusion coefficient is obtained, and no restricted diffusion occurs. At 4 wt \% STDC and $X_{D D A B}=0-0.36$, the decrease in $D / D_{0}$ is not very significant. However, at $\mathrm{X}_{\mathrm{DDAB}}=0.38$ (region III), the upper dispersion shows a pronounced decreasein $D / D_{0}$, while the lower dispersion shows a value cl ose to that of neat water. These results are consistent with the much higher viscosity of the upper dispersion. On theother hand, it is interesting to notethat in thelower bluish dispersion, $\mathrm{D} / \mathrm{D}_{\mathrm{o}}$ is comparable to that for the neat bile salt micellar solution. $D / D_{0}$ for the concentrated $L_{1}$ varies between 0.2 and 0.5 , consistent with high obstructing volume (high viscosity) for these solutions.

A global analysis of the self-diffusion study all ows some conclusions with respect to phase microstructure. The DDAB self-diffusion in the bluish dispersion is similar to that in the concentrated $L_{1}$ phase, but slightly faster due to the dilution effect (lower obstructing volume).This fact supports the view that the bluish liquids consists of a fine dispersion of $L_{1}$ in a diluted solution. The discrepancy found between the STDC and DDAB coefficients in the bluish dispersions (not seen in the concentrated $L_{1}$ ) can bereasonably explained. Thefaster STDC diffusion results most probably from theaveraging of the diffusion of "pure" STDC micelles in the diluted sol ution (fast diffusion) and themixed aggregates in the concentrated $L_{1}$ domains (slow diffusion). This averaging requires a fast exchange of STDC monomer between the two aggregates. Some evidence for this interpretation comes from cryo-TEM observations, where small micelles appear to coexist with the large domains (data not shown here). In turn, the water diffusion for the double dispersion allows some speculation on its structure. The microscopy results indicatea droplet structurefor both dispersions. Thewater and surfactant diffusion are consistent with the upper birefringent dispersion being a highly concentrated dispersion of aggregated $L_{1}$ domains (droplets) in the $L$ phase or a dilute dispersion of $L$ droplets in $L_{1}$. The lower bluish 


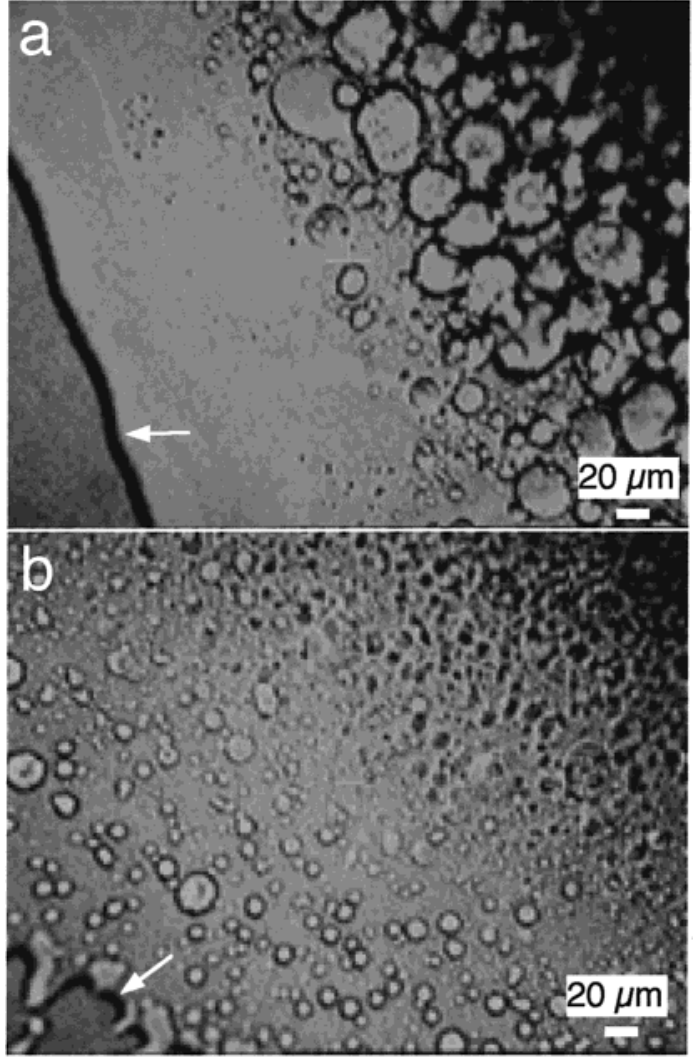

Figure 8. Light microscopy imaging of a samplein the double dispersion region, at 3.9 wt \%STDC, 2.2 wt \%: (a) upper phase; (b) lower phase. The arrows indicate the air-liquid boundary for the sample in the glass slide.

Table 2. Surfactant Self-Diffusion Coefficients Obtained from PFG NMR in the Solutions and Bluish Dispersions of the STDC-DDAB-Water System at $25^{\circ} \mathrm{C}$

\begin{tabular}{ccccccc}
\hline $\begin{array}{c}\text { STDC } \\
\text { (wt \%) }\end{array}$ & $\begin{array}{c}\text { DDAB } \\
\text { (wt \%) }\end{array}$ & $\mathrm{X}_{\text {DDAB }}$ & $\begin{array}{c}\text { phase } \\
\text { behavior }\end{array}$ & $\begin{array}{c}\mathrm{D}_{\mathrm{STDC}} \\
\left(10^{-12}\right. \\
\left.\mathrm{m}^{2} \mathrm{~s}^{-1}\right)\end{array}$ & $\begin{array}{c}\mathrm{D}_{\mathrm{DDAB}} \\
\left(10^{-12}\right. \\
\left.\mathrm{m}^{2} \mathrm{~s}^{-1}\right)\end{array}$ & $\begin{array}{c}\mathrm{R}_{\mathrm{H}}{ }^{\mathrm{a}} \\
(\mathrm{nm})\end{array}$ \\
\hline 4.0 & 0 & 0 & $\mathrm{~L}_{1}$ & 91 & & 1.7 \\
4.0 & 0.2 & 0.06 & $\mathrm{~L}_{1}$ & 85 & 76 & 2.5 \\
4.0 & 0.9 & 0.20 & $\mathrm{~L}_{1}$ & 51 & 44 & 4.4 \\
3.9 & 2.0 & 0.36 & region I & 8.7 & 2.9 & 321 \\
3.9 & 2.2 & 0.38 & region IIb & 1.5 & 0.34 & 572 \\
3.9 & 2.2 & 0.38 & region IIc & 24 & 11 & 17.2 \\
7.5 & 3.1 & 0.32 & region I & 46 & 18 & 11.0 \\
8.6 & 4.5 & 0.30 & region I & 0.79 & 0.85 & 304 \\
25.3 & 6.0 & 0.21 & $\mathrm{~L}_{1}$ & 0.65 & 0.47 & 413 \\
28.7 & 10.9 & 0.30 & $\mathrm{~L}_{1}$ & 0.61 & 0.61 & 321 \\
30.0 & 12.9 & 0.33 & $\mathrm{~L}_{1}$ & 0.60 & 0.65 & 299 \\
34.6 & 30.5 & 0.49 & $\mathrm{~L}_{1}$ & 0.78 & 1.1 & 250 \\
37.06 & 28.1 & 0.46 & $\mathrm{~L}_{1}$ & 0.76 & 0.90 & 258
\end{tabular}

a Values calculated from $D_{\text {DDAB }}{ }^{b}$ Region II (upper phase). c Region II (lower phase).

dispersion must then be essentially a diluted dispersion of $L_{1}$ droplets in $L$. The reasons behind their equilibrium phase separation remain puzzling and require further investigations.

\section{Summary and Final Remarks}

The STDC-DDAB-water system illustrates a catanionic system in which several uncommon phase behavior features are observed. At room temperature, two single-phase regions are observed in the bile salt-rich area: a wideisotropic solution, extending to equimolarity, and a hexagonal liquid-crystalline phase, which incorporates small amounts of DDAB. Self-diffusion and cryo-
Table 3. Water Self-Diffusion Coefficients in the Solution and Dispersions of the STDC-DDAB-Water System at $25^{\circ} \mathrm{C}$

\begin{tabular}{ccclcc}
\hline $\begin{array}{c}\text { STDC } \\
\text { (wt \%) }\end{array}$ & $\begin{array}{c}\text { DDAB } \\
\text { (wt \%) }\end{array}$ & XDAB $_{\text {DDA }}$ & $\begin{array}{c}\text { phase } \\
\text { behavior }\end{array}$ & $\begin{array}{c}\mathrm{D}_{\mathrm{HDO}} \\
\left(10^{-9} \mathrm{~m}^{2} \mathrm{~s}^{-1}\right)\end{array}$ & ${\mathrm{D} / \mathrm{D}^{\mathrm{a}}}^{\mathrm{a}}$ \\
\hline 4.0 & 0 & 0 & $\mathrm{~L}_{1}$ & 1.81 & 0.951 \\
4.0 & 0.9 & 0.20 & $\mathrm{~L}_{1}$ & 1.77 & 0.932 \\
3.9 & 2.0 & 0.36 & region I & 1.69 & 0.891 \\
3.9 & 2.2 & 0.38 & region I & 1.19 & 0.624 \\
3.9 & 2.2 & 0.38 & region II & 1.86 & 0.980 \\
25.3 & 6.0 & 0.21 & $\mathrm{~L}_{1}$ & 1.03 & 0.542 \\
28.7 & 10.9 & 0.30 & $\mathrm{~L}_{1}$ & 0.808 & 0.425 \\
30.0 & 12.9 & 0.33 & $\mathrm{~L}_{1}$ & 0.702 & 0.369 \\
37.1 & 28.1 & 0.46 & $\mathrm{~L}_{1}$ & 0.316 & 0.166
\end{tabular}

a Ratio between the observed diffusion coefficient, $\mathrm{D}$, and that for neat water (HDO), $D_{0}=1.90 \times 10^{-9} \mathrm{~m}^{2} \mathrm{~s}^{-1}$. b Region I (upper phase). ${ }^{\mathrm{C}}$ Region II (lower phase).
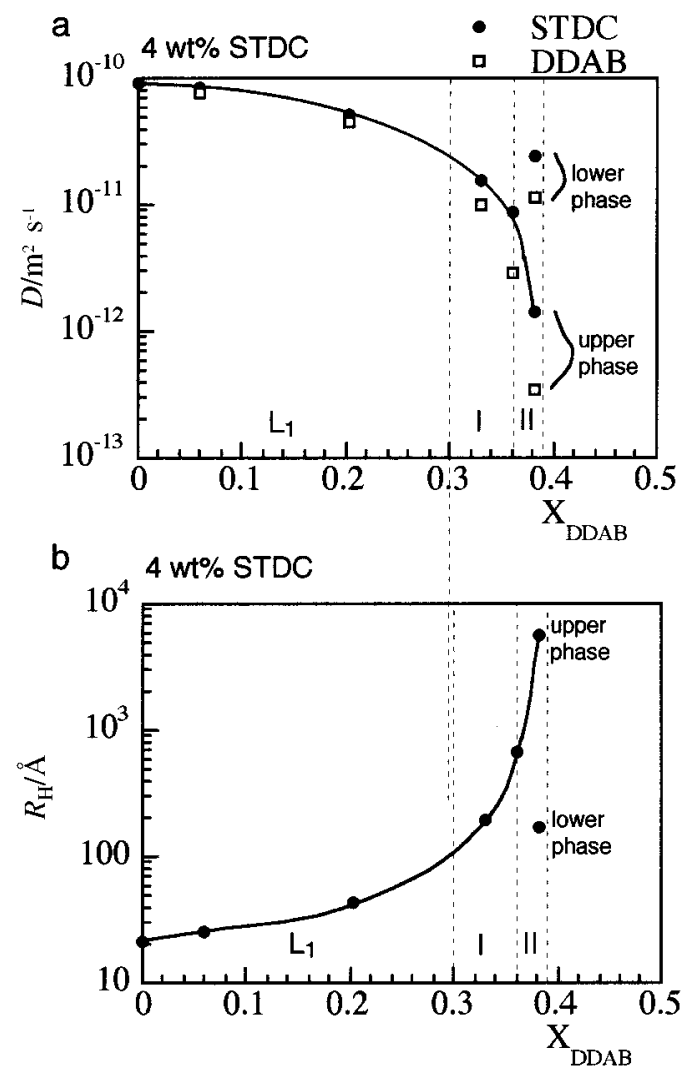

Figure 9. Self-diffusion measurements in the diluteregion of theSTDC-DDAB - water system, at $25^{\circ} \mathrm{C}$ : (a) surfactant selfdiffusion; (b) hydrodynamic radius calculated from the selfdiffusion coefficient values for DDAB. The lines are guides for the eye.

TEM data show that the mixed micellar aggregates in the $L_{1}$ region do not grow significantly, neither as a function of DDAB nor of total surfactant concentration. The hexagonal Ic phase has been tentatively assigned to a reversetypestructure. ${ }^{17,18}$ Thedestabilization of a reverse hexagonal phase by addition of DDAB then appears somewhat curious, since DDAB in principle would comfortably pack in a structure of negativecurvature, as seen for instance in the DDAB-AOT system. ${ }^{43}$ The easy perturbation of the Ic phase by the flexible chain amphiphile thus suggests a highly nonconventional reverse type structure. From the phase diagram, it follows that the isotropic solution phase is favored upon DDAB addition. So one can speculate on the diverse structure of theaggregates in the lc phaseand in the $L_{1}$ phase, despite the "proximity" in bulk composition. No cubic liquidcrystalline phase is formed around equimolar composi- 
tions, in contrast to several bile salt-surfactant systems ${ }^{20,28,34}$ and catanionic systems in general. 37,43,59

The region between the $L_{1}$ phase and the equimolar lineis a two-phaseregion composed of $L_{1}$ and a very dilute solution (almost pure water), where the macroscopic separation between thephases takes somepeculiar aspects upon DDAB addition. Equimolarity is dominated by "true" coacervation, i.e., complete macr oscopic phaseseparation of thetwo solutions. The intermediateregion of the phase diagram is dominated by a very fine bluish dispersion of $\mathrm{L}_{1}$ in the diluted phase. While the bluish dispersion is in equilibrium with the diluted phaseat higher $\mathrm{X}_{\mathrm{DDAB}}$ (region III), at lower $X_{D A A B}$ it occurs on its own (region I) or separates into a concentrated and a dilute dispersion (double dispersion region). As DDAB is further added, the concentrated $L_{1}$ domains graduall y separatefrom the almost pure water phase, and this is eventually attained at around equimolarity.

For most common catanionic surfactant systems, the concentrated phase is either a precipitate or a liquidcrystalline phase. ${ }^{42}$ This is not the case for the STDCDDAB mixture, where the mixed aggregates at equimolarity retain the micellar structure. Moreover, vesicle formation, often detected in catanionic mixtures, is absent from the diluted bile salt-rich area of the system. This absence is to some extent surprising since DDAB is a

(59) Edlund, H.; Sadaghiani, A.; Khan, A. Langmuir 1997, 13, 4953. bilayer-forming surfactant and thebilesalt has a versatile amphi philicstructure. Thecurrent systemillustrates the effectiveness of both STDC and DDAB as dispersants (or emulsifiers). The bile salt is the highly efficient fat emulsifier in the body, its biological importance thereof derived. 3,7 DDAB is known to form extensive regions of microemulsions with a number of oils. ${ }^{60}$ The two amphiphiles in combination show strong synergistic properties. These observations areprobably generalized to other types of bile salt-double-chained surfactant mixtures, but the electrostatic effects in catanionic systems are likely to enhance the dispersive power.

Acknowledgment. Camillo La Mesa is kindly acknowledged for many valuable discussions. The Swedish Research Council for Engineering Sciences (TFR) and PRAXIS XXI, Portugal (project 2/2.1/QUI/411/94), are gratefully acknowledged for financial support. H.E. gratefully acknowledges STINT (The Swedish Foundation for International Cooperation in Research and Higher Education) for a Postdoctoral Schol arship in the Department of Chemical Engineeering, University of Delaware.

\section{LA0002278}

(60) Warr, G. G.; Sen, R.; Evans, D. F.; Trend, J . E. J . Phys. Chem. 1988, 92, 774 . 